\title{
Demand of Electric Energy at National Level, and Its Impact on National Growth 1988-2014
}

\author{
Danae Duana Avila, Tirso Javier Hernández Gracia, Karina Valencia Sandoval, \\ Sergio Demetrio Polo Jiménez
}

Universidad Autónoma del Estado de Hidalgo, Pachuca de Soto, Hidalgo, México

Email: duananos@yahoo.com.mx,duana@uaeh.edu.mx

How to cite this paper: Avila, D. D., Gracia, T. J. H., Sandoval, K. V., \& Jiménez, S. D. P. (2017). Demand of Electric Energy at National Level, and Its Impact on National Growth 1988-2014. Advances in Applied Sociology, 7, 341-347.

https://doi.org/10.4236/aasoci.2017.710022

Received: January 31, 2017

Accepted: October 27, 2017

Published: October 30, 2017

Copyright $\odot 2017$ by authors and Scientific Research Publishing Inc. This work is licensed under the Creative Commons Attribution International License (CC BY 4.0).

http://creativecommons.org/licenses/by/4.0/

\begin{abstract}
The energy sector has a positive impact within the national GDP in Mexico with US795471.185. The electricity age began in Mexico in 1849, after it began in the United States and Europe. On the other hand, the adequate consumption of energy is indispensable for the economic and social development of a country. The electric power industry is one of the fundamental pillars on which the economy of all countries is based, so that the operation of this sector directly affects the economic growth of Mexico. The current situation in Mexico requires changing the way energy is produced and consumed to ensure sustainable economic development. The world is now facing the challenge of combating climate change, while pursuing economic growth and an equitable distribution of wealth. Electricity cannot be stored because higher costs, so demand and supply must be absolutely balanced in real time. A number of countries, such as the USA, China, Brazil, Japan and Russia, are in a continuous process with a common objective: to provide a reliable and economical electric service. However, in Mexico, the 2013 constitutional reform was implemented, which promotes the improvement of Mexican economies, with the main objective of reducing the cost of electricity and gas. The present research is an approach to the behavior of the energy market.
\end{abstract}

\section{Keywords}

Energy, Electricity Sector, Econometric Model, Substitute Goods

\section{Introduction}

The process of economic internationalization is the result of a tendency towards greater integration between countries, curiously through a geographical fragmentation of the stages of the productive process carried out by the companies 
and that is based to a large extent on the expansion of the Multinational companies. This is not a phenomenon that necessarily refers to large companies since there are small companies that can be highly transnationalized due to their high relation with external capital. To analyze the energy saving organizational practices and verify if they have a significant impact on their financial results can maximize the Net Social Value (VSN) of demand, production costs and energy distribution.

For some authors (García, 2007) the explanatory factors of family are found in market conditions and in technology. The market forces multinationals to respond to strategic growth and expansion needs related to their technical process. One of the strategies to meet these needs is the international restructuring of production, which is based on transferring abroad productive processes in which the industrialized countries have lost international comparative advantages. Stephen Hymer and Christian Palloixs (Palloix, 1975) peak of organic restructurings, both vertically and horizontally, carried out by multinational corporations.

\section{Methodology}

A mathematical model was developed to describe the behavior of energy demand, based on the 2013 constitutional reform, which promotes the improvement of Mexican economies by lowering the cost of electricity and gas receipts. The behavior of the family or consumer unit comprises a number of aspects, quite rightly, can arouse the curiosity of the cultivators of the social sciences. This relationship is of special interest and necessary in the evaluation of a wide range of national projections to determine the total impact of policies related to energy consumption, as well as in the simulation of models for the analysis of future optimization situations. It is possible to calculate the elasticities as independent variables that affect the dependent variable (Oil \& Gas Journal, 2015).

Since this is a study of the behavior of the family unit, it is logical to use this unit as the centerpiece of the analysis. To do this, we will first specify the theoretical context in which the family unit works and only when we have examined all the possible implications for microeconomic behavior theory can we proceed, even with extreme caution, to complete the study with the relations Macroeconomic conditions. Analyze the organizational practices of energy saving and verify if they have a significant impact on their financial results.

These economically significant macroeconomic relationships, in opposition to simple statistical curiosities or ad hoc regularities, exist only when it is possible to refer their origins by explicit specifications of a theoretical and probabilistic nature to the underlying microeconomic analysis.

The laws of economics are empirically valid once the process that generates the sample observations has been identified. All economic models, by the mere fact of being, require simplifying assumptions (sometimes judged as drastic or unreal by non-economists).

The current situation in Mexico requires changing the way energy is produced and consumed to ensure sustainable economic development, while meeting energy 
needs through the rational use of resources and technologies.

Energy efficiency is the way to this energy transition; is the solution that allows the rational use of energy while maintaining the levels of competitiveness. In Mexico there is the Energy Secretariat (SENER) which recognizes the importance of this issue as the center of a solid and sustainable energy policy (SENER, 2014).

The energy efficiency indicators allow to evaluate the results of public policies and actions implemented in this area, as they describe and indicate in detail how energy is being used in different sectors of the economy. However, in order to construct appropriate indicators, it is extremely important to have a database with reliable, congruent, truthful, timely and constantly updated information.

Today, the world is facing the challenge of combating climate change, while pursuing economic growth and an equitable distribution of wealth. The energy sector plays an important role in the economic and social development of a country. Therefore, it is fundamental to change the way in which the country produces and consumes energy to ensure a more sustainable future.

For the UK one of its top priorities is to help promote a low-carbon global economy with high economic growth. The UK has built a series of strategic relationships with partners in various countries. The United Kingdom is particularly proud of the cooperation and joint work program with Mexico and the added value it has generated in the international debate on issues of growth and climate change as well as the action plans of both economies on these issues (NaturalGasIntel.com, 2015).

\subsection{Economic History of Institutions in the Mexican Electricity Sector}

The electricity age began in Mexico shortly after it began in the United States and Europe. In Mexico, electric power had an important role to play in the Mexican economic deployment at the start of the 20th century. The national electric network arises in 1879 in the city of Leon, Guanajuato. The first power plants in Mexico were used in mining to illuminate the dens of the mines and, in the industry, to start motors and looms. At the beginning the electric era in Mexico, the regulation was at the regional level, this changes at the end of the government of Porfirio Diaz, the regulation at the federal level is extended and the doors are opened to the investments of foreign electric companies, giving guarantees to the foreign capital (García, 2007).

In 1907, the hydroelectric company Chápala reorganized itself and, by counting three plants, renamed Guadalajara Tramway Co, the group had as subsidiaries the Morelia power company, the Guzmán power company, the western hydroelectric company, the Manzanillo power company and the Mexican electric company (Díaz, 2005).

In the 21st century, the demands of the development of the electricity sector, technological changes and the transformation of the conditions in which it operates, are no longer compatible with the current scheme. 
The electric power industry is one of the fundamental pillars on which the economy of all countries is based, so that the operation of this sector directly affects the economic growth of Mexico. The economy and market powers are driving profound changes in the electricity sector. The electricity system is made up of three sectors: the generation sector, the transmission sector and the distribution sector (New York Times, 2015).

\subsection{Activities of the Mexican Electrical Industry}

The electric energy is not a natural resource; it is a good that man produces and that by its physical characteristics it is not possible to store. The generation, transmission, distribution and sale of electric energy that have as purpose the provision of the public service were activities of exclusive competence of the Federal Electricity Commission (CFE), throughout the national territory, now with the energy reform there is an electric opening which allows the private investment of companies, which have the possibility to generate and supply this type of energy and compete with the CFE.

\subsection{Global Electrical Restructuring and Regulation of the Electricity Sector}

The world is experiencing a time of great changes in the electric sector. Several countries and companies are in a continuous process with a common Objective: to provide a reliable and economic electric service. The means used to achieve this goal are affected by various factors such as the development of technology, the state and the degree of development of the economy, as well as environmental regulations and policies and political and economic processes.

Regulation is the pursuit of economic efficiency, by reducing the presence of monopolistic structures or imperfect competition that cause price systems do not reflect the real opportunity costs of usable resources.

\subsection{Energetic Reform}

The behavior of the family or consumer unit comprises a number of aspects, quite rightly, can arouse the curiosity of the cultivators of the social sciences. Of course, economists focus their attention on economic aspects, and generally leave aside the sociological, demographic and psychological characteristics of household behavior, considering them irrelevant because of their circumstantial character, the reason for this isolation of the key variables Suppressing the others seems clear: we intend to link certain variables by means of a (manageable) set of behavioral relations (what is known by a model) in order to explain, and if possible to predict, changes in the values of the Variables, by studying different family units both at a particular time and over a period of time (Oil \& Gas Journal, 2015).

Given the limited capacity of our minds and computers, the number of variables and the complexity of the model can vary widely, depending on our resources and ambitions. To do this, we will first specify the theoretical context in which the family unit works and only when we have examined all the possible 
implications for microeconomic behavior theory can we proceed, even with extreme caution, to complete the study with the relations Macroeconomic conditions. These economically significant macroeconomic relationships, in opposition to simple statistical curiosities or ad hoc regularities, exist only when it is possible to refer their origins by explicit specifications of a theoretical and probabilistic nature to the underlying microeconomic analysis. The laws of economics are empirically valid once the process that generates the sample observations has been identified. If we do not accept this view, we will have no defense against the inexact empirical approach, in which the only theory is: " $\mathrm{C}$ can be explained by a set $N$ of variables, $X_{1} \cdots X_{N}$ and a series of associated error terms" (BP, 2015).

Considering, for example, the following somewhat "capricious" explanation of consumption: "Consumption of the family unit is a function of its income, of the age and occupation of the head of household, of the number of age, of age and sex of the other members of the family, race, national origin, community size, region of the country, whether the household owns or leases its home, the years of education, The type of education and professional training, religious affiliation and the number of cars owned by the family. Given this amount of information, one should really be able to give the head's name and predict its consumption expenditures. This is not a model; is a simple description lacking in purchasing power".

\subsection{About the Methodology}

All economic models, by the mere fact of being, require simplifying assumptions (sometimes judged as drastic or unreal by non-economists). In particular, the model-maker is faced with the problem of having to postulate the fundamental motivation that lies behind all the decisions and actions of the family union.

There are several alternatives: we could assume that family units act according to an empirical law that dictates that their consumption expenditures should be proportional to their computed income (possibly being the proportionality factor equal to unity this coarse specification might work reasonably well for some purposes, However, such a rigid model for the behavior of the family unit does not give the family any rational margin of response to the various situations it faces.

In recent years, the number of phenomena investigated by theoretical economists receiving an optimization theory approach has increased (Lancaster, 1968). Increasingly, economists come to the conviction that when a variable is subject to control of a decision unit, the most fruitful way to describe the superstructure of the model is in terms of an index that, subject to one or more constraints, The unit that makes the decision tends to maximize (or minimize) (Lancaster, 1968).

It is unnecessary to say that the particular applications of the method define according to the type of problem studied; in business theory, for example, the index to be minimized, subject to the constraint of maintaining a given level of output, may be the total input cost. On the other hand, in the neoclassical theory 
of demand, the index is the utility function, and the constraint to be submitted is the socio-legal requirement that planned merchandise purchases do not exceed expected revenues. This restriction optimization theory is highly suitable for the purposes of this book, and therefore we can practice it in many different ways.

\section{Results}

Given the limited capacity of our minds and computers, the number of variables and the complexity of the model can vary widely, depending on our resources and ambitions.

Most of the work will be devoted to exposing the different theories about the behavior of the consumption unit, presenting less attention to the presentation and review of the enormous amount of empirical results. Our study begins with Keynes's consumption function (as opposed to the so-called Keynesian function of consumption) and follows the development of theory, or theories, to this day, including the current emphasis on $\mathrm{W}$ as the fundamental explanatory variable.

To do this, we will first specify the theoretical context in which the family unit works and only when we have examined all the possible implications for microeconomic behavior theory can we proceed, even with extreme caution, to complete the study with the relations Macroeconomic conditions. These economically significant macroeconomic relationships, in opposition to simple statistical curiosities or ad hoc regularities, exist only when it is possible to refer their origins by explicit specifications of a theoretical and probabilistic nature to the underlying microeconomic analysis. The laws of economics are empirically valid once the process that generates the sample observations has been identified. If we do not accept this view, we will have no defense against the inexact empirical approach, in which the only theory is: Considering, for example, the following somewhat "capricious" explanation of consumption, of the number of age, of age And sex of the other members of the family, race, national origin, community size, region of the country, whether the household owns or leases its home, the years of education, the type of education and professional training, religious affiliation and the number of cars owned by the family. Given this amount of information, one should really be able to give the head's name and predict its consumption expenditures. Any process of deregulation must consider the fundamental concepts of electric markets in order to determine if prices have a positive effect on the demand for electricity, a linear regression was run:

$$
\begin{aligned}
L_{j t}^{D}=\beta_{0} & +\beta_{1}\left(P G L P_{j t t}\right)+\beta_{2}\left(P G N_{j t}\right)+\beta_{3}\left(P E L E C_{j t}\right)+\beta_{4}\left(P I B_{j t}\right)+\beta_{5}(P O B) \\
E= & 34378.05-0.203338 P E L E C-2.339178 P G L P-7.687793 P G N \\
& +7.91 E-6 P I B+0.5145 P O B+e
\end{aligned}
$$

In order to determine if the prices of substitute goods have a positive effect on demand for electricity, the above Equation (2) shows that prices are statistically significant because the statistical value is $t=7.544296$ is greater than Critical value of the distribution $t$ for 20 degrees of freedom a level of significance of $5 \%$ (2086). The coefficient is 0.20 means that an increase in demand. 


\section{Conclusion}

Therefore, it is fundamental to change the way in which the country produces and consumes energy to ensure a more sustainable future, migrate to more efficient lighting systems, promote the replacement of inefficient appliances, install high performance electric motors and pumps in the industry, establish building codes that promote energy efficiency, and expand industrial heat recovery systems. It is essential to have adequate information to monitor the evolution of these actions.

The world is now facing the challenge of combating climate change, while pursuing economic growth and an equitable distribution of wealth. The energy sector plays an important role in the economic and social development of a country. Therefore, it is fundamental to change the way in which the country produces and consumes energy to ensure a more sustainable future.

Energy efficiency is the way to this energy transition; is the solution that allows the rational use of energy while maintaining the levels of competitiveness. In the 21 st century, the demands of the development of the electricity sector, the technological changes and the transformation of the conditions in which it operates, are no longer compatible with the current scheme.

\section{References}

BP (2015). BP Statistical Review of World Energy 2015.

http://www.bp.com/en/global/corporate/about-bp/energy-economics/statistical-review -of-worldenergy

Díaz, A. (2005). International Experiences in Electric Deregulation and in the Electricity Sector in Mexico (pp. 26-165). México: Plaza y Valdés.

García, J. (2007). Origin of Energy and Its Effects (pp. 17-118). Mexico: National Polytechnic Institute.

Lancaster, J. (1968). On the Evolution of Tool-Using Behavior. American Anthropologist, 70, 56-66. http://dx.doi.org/10.1525/aa.1968.70.1.02a00060

Natural GasIntel.com (2015). Mexico’s \$10B in Infrastructure Projects Includes NatGas Pipeline under GOM.

http://www.naturalgasintel.com/articles/102760-mexicos-10b-in-infrastructure-project s-includes-natgaspipeline-under-gom

New York Times (2015). With Oil Revenue Dropping, Mexico Announces Budget Cuts. http://www.nytimes.com/2015/01/31/world/americas/with-oil-revenue-dropping-mexi co-announces-budget-cuts.html?_r=2

Oil \& Gas Journal (2015). Worldwide Look at Reserves and Production.

Palloix, C. (1975). Multinational firms and the process of internationalization, Siglo XXI.

SENER (2014). SENER Natural Gas Prospectus 2014.

http://www.energia.gob.mx/res/ProspectivaDeGasNaturalyGasLP2014.pdf 